\title{
Our Experience with Pirfenidone in Patients with Idiopathic Pulmonary Fibrosis
}

\author{
Berna Akıncı Özyürek ${ }^{1}$,Yurdanur Erdoğan ${ }^{1}$, Nilgün Yllmaz Demirci², \\ Sertaç Büyükyaylacı Özden ${ }^{1}$, Tuğçe Şahin Özdemirel ${ }^{1}$ \\ ${ }^{1}$ Clinic of Chest Diseases, Atatürk Chest Diseases and Chest Surgery Training and Research Hospital, Ankara, Turkey \\ ${ }^{2}$ Clinic of Chest Diseases, Gazi University Training and Resarch Hospital, Ankara, Turkey
}

Idiopathic pulmonary fibrosis (IPF) is a chronic, progressive, mortal disease of unknown cause that is characterized by an irreversible pulmonary function loss and progressive pulmonary fibrosis. There is no standard treatment for IPF. Pirfenidone, approved by the Food and Drug Administration for the treatment of IPF, is an oral drug having antifibrotic, anti-inflammatory, and antioxidant effects. Pirfenidone limits the decline in pulmonary function tests and disease progression in patients with extended fibrosis (1).

Eight patients diagnosed with IPF for whom pirfenidone was initiated between 2013 and 2015 were included in the study. The results of the patients' pulmonary function test and 6-min walk test (6MWT) before and 1 year after treatment were recorded. The quality of life was evaluated before and 1 year after treatment using the St. George's Respiratory Questionnaire (SGRQ). Descriptive statistical methods were used. The study was approved by the hospital's ethics committee.

Five male and three female patients were enrolled; the mean age was 58.25 years. Six patients had a 30 packs.year smoking history. Five patients with possible UIP pattern on radiological examination were diagnosed with IPF via an open lung biopsy; three were clinically and radiologically diagnosed. Pirfenidone treatment was initiated in patients diagnosed with IPF whose FVC was $>50 \%$, DLco was $>30 \%$ in pulmonary function test, and walking distance was $>150 \mathrm{~m}$ in $6 \mathrm{MWT}$. For all patients, pirfenidone dosage was $3 \times 1$ tablets for the first week, $3 \times 2$ for the second week, and $3 \times 3$ tablets from the $15^{\text {th }}$ day onward. For controls, the patients were examined in the first and second week and first, third, sixth, ninth, and twelfth months following treatment initiation. At treatment initiation and during follow-up, the patients' laboratory tests were normal. The average treatment duration was 12.8 (1-23) months. Mean FVC before and after treatment was $2.17 \mathrm{lt}, 63 \%$ and 2.33 It, $67.6 \%$ respectively. Mean DLco before and after treatment were $63.4 \%$ and $64.4 \%$, respectively. When compared, a 33.2\% increase was observed in 6MWT after treatment. During treatment, no exacerbations occurred. The total SGRQ scores before and after treatment were 55.4 and 32.4, respectively (Table 1).

Pirfenidone and nintedanib have been recently approved for the treatment of IPF after demonstrating an efficacy in slowing functional decline and disease progression (2). Pirfenidone demonstrates anti-fibrotic effect via cytokines and transforming growth factors. In the studies performed with pirfenidone, the drug decelerated the disease progression rate and the loss in pulmonary function tests (3-5). Exacerbations were observed less in the group using pirfenidone (3). The survival rate without progression was higher in the group using pirfenidone compared with that in the group using placebo $(4,5)$. Pirfenidone decelerated the decline in 6MWT (5). The most frequent side effects were skin-related events, gastrointestinal symptoms (nausea, vomiting, and dyspepsia), and increase in liver function tests (3-5). Serious side effects were observed in $1 \%-5 \%$ of patients (5). We observed deceleration in the loss in pulmonary function tests and improvement in 6MWT in our patients. There was a significant improvement in the quality of life according to SGRQ. No exac- 
Table 1. Our patients' age and gender and FVC, 6MWT, and SGRQ total score values before and after treatment

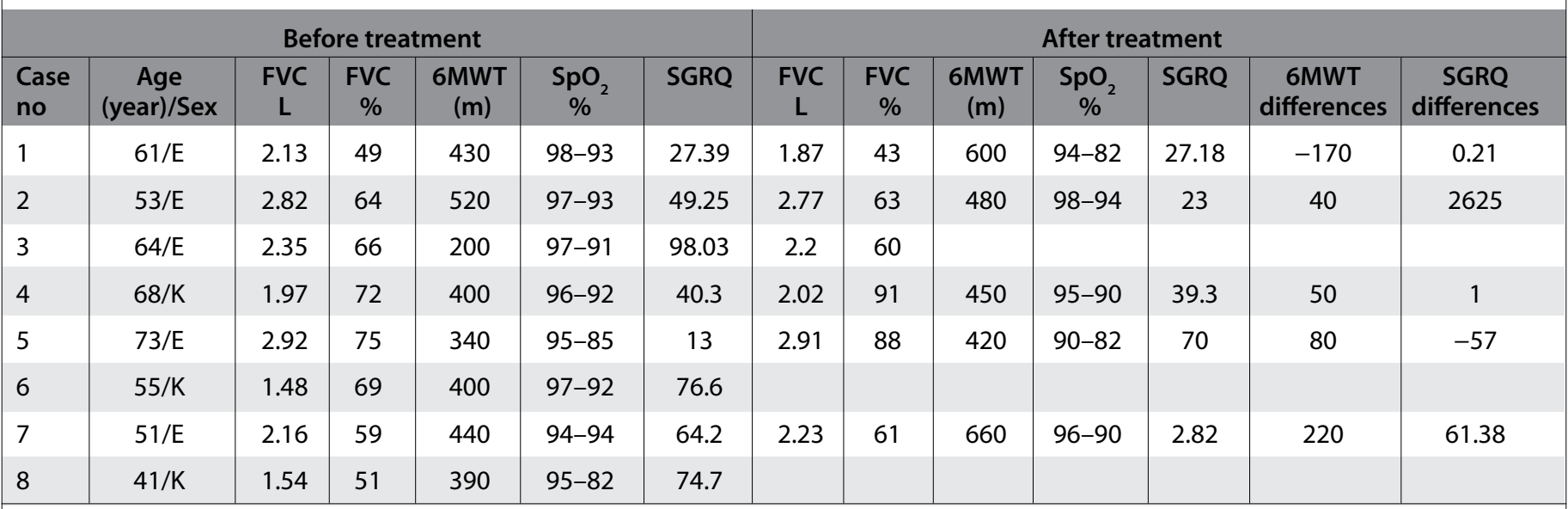

FVC: Forced vital capacity; SGRQ: St. George's Respiratory Questionnaire; approval forms were taken from the patients; $\mathrm{SpO}_{2}$ : Oxygen saturation; $6 \mathrm{MWT}$ : 6-min walk test

erbations occurred during the 1-year follow-up period. Dyspepsia was observed in five patients, whereas gastrointestinal bleeding was observed in one patient. Skin-related events were not noted in patients. We observed that pirfenidone decelerated disease progression, reduced exacerbations, and improved the quality of life. Furthermore, we can state that pirfenidone is more reliable than previously used drugs in terms of side effects.

\section{REFERENCES}

1. Spagnolo P, Del Giovane C, Luppi F, Cerri S, Balduzzi S, Walters EH, et al. Nonsteroid agents for idiopathic pulmonary fibrosis. Cochrane Database Syst Rev 2010; 9: CD003134.
2. Bonella F, Stowasser S, Wollin L. Idiopathic pulmonary fibrosis: current treatment options and critical appraisal of nintedanip. Drug Des Devel Ther 2015: 9: 6407-19.

3. Azuma A, Nukiwa T, Tsuboi E, Suga M, Abe S, Nakata K, et al. Double-blind, placebo-controlled trial ofpirfenidone in patients with idiopathic pulmonary fibrosis. Am J Respir Crit Care Med 2005; 171: 1040-7. [CrossRef]

4. Taniguchi H, Ebina M, Kondoh Y, Ogura T, Azuma A, Suga M, et al. Pirfenidone in idiopathic pulmonary fibrosis. Eur Respir J 2010; 35: 821-9. [CrossRef]

5. Noble PW, Albera C, Bradford WZ, Costabel U, du Bois RM, Fagan EA, et al. Pirfenidone for idiopathic pulmonary fibrosis: analysis of pooled data from three multinational phase 3 trials. Eur Respir J 2016; 47: 243-53. [CrossRef] 